\section{ESTRATÉGIA E LIDERANÇA: AS LICOÕES DOS MESTRES CHINESES NA VISÃO DE UM OCIDENTAL}

de THOMAS CLEARY

São Paulo: Saraiva, 1994, 133 p.

por Marcia Regina Dantas, Doutoranda na EAESPIFGV.

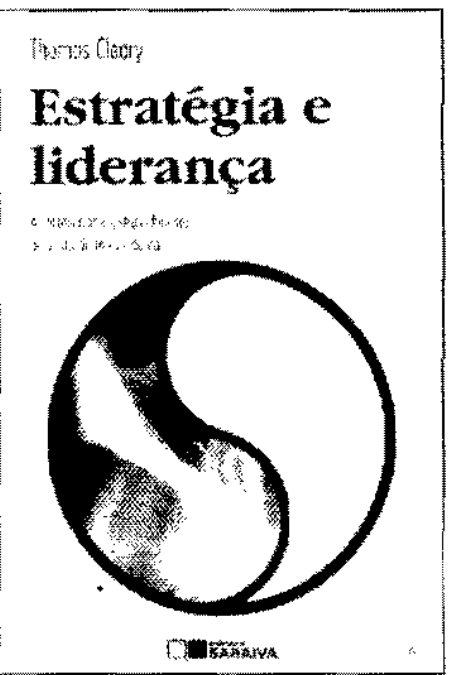

$\mathbf{H}$ oje, mais do que nunca, existe no meio empresam rial uma crescente preocupação com as mudanças que vêm ocorrendo em todo o mundo, mudanças essas que estão trazendo, para as organizações, novas necessidades, pois os tradicionais parâmetros de desempenho e de produtividade não mais são suficientes para responder aos cenários atuais de competitividade. Assim, a busca de uma estratégia que atenda a esses novos paradigmas está se tornando uma constante, e não apenas por parte da alta administração, mas de toda uma estrutura preocupada com a sobrevivência da empresa, a médio e longo prazos. Conseqüentemente, observamos as mais diversas organizaçôes se lançarem na busca de novos métodos e/ ou sistemas que thes possam garantir o sucesso efetivo.

No livro Estratégia e lideranga: as liçôs dos mestres chineses, Thomas Cleary nos mostra que mudanças são um tema täo antigo quanto o mundo e que a cada nova êpoca novos paradigmas surgem e novas estratégias são postas em prática. Porém, em todas as épocas, o ser humano tem sido o elemento-chave para entender as mu- danças e superá-las, usando o instrumento que the é mais peculiar: seu pensamento.

Especialista em civilizaçöes da Ásia Oriental, o autor apresenta uma coletânea de pensamentos sobre a arte de administrar e de governar, cuja base filosófica pode ser encontrada nas filosofias orientais, especialmente no Taoísmo. Tais pensamentos transmitem ensinamentos preciosos relativos aos desafios da liderança, $\mathrm{e}$ mesmo datando de dois mil anos ou mais mantêm sua atualidade.

Como outros textos sobre filosofia oriental, este livro se volta mais à orientação do que à doutrinação e, diferentemente do que se vê nos últimos tempos, não apresenta receitas prontas para o sucesso, apenas mostra que este, para ser alcançado, só depende de um elemento: a capacidade do ser humano de olhar o mundo que o cer$\mathrm{ca}$, com olhos de ver, e tratar as pessoas que nele vivem, e com quem ele - ser humano - interage, de modo ético.

O livro está dividido em quatro partes: Estado e Sociedade, Bem-Estar Paz e Sabedoria. Em cada uma de las nos são apresentados, em linguagem de fácil eñtendimento, pensamentos profundos, que são pérolas de estratégia. Senẫo vejamos: "Mesmo os líderes sábios devem esperar as circunstâncias adequadas, que só podem ser encontradas no tempo certo..." Nesta era, onde a administraçäo do tempo e crucial e onde processos do tipo just-in-time são exaltados, não existe melhor definição do que a supracitada para justificar a premissa de que oportunidade é fundamental, e não depende de nós forçá-la, mas tão-somente aproveitá-la.

Outro aspecto relevante dos tempos atuais, freqüentemente abordado pela administração, diz respeito à perfeita adequação profissional / função. Para contemplar este tópico, o autor nos oferece, entre tantas outras, a seguinte reflexäo: "Quando as pessoas não são escolhidas, nem reconhecidas, isso não significa que sejam desprovidas de mérito, mas apenas que as furçôes que thes são oferecidas não säo indicadas para elas".

No que diz respeito à Paz, Thomas Cleary nos mostra sua dimensăo pela antítese, isto ê, fala-nos da guerra como modo reflexivo para alcançá-la, e nos diz que "...tm exército que permanece integro só vai para a guerra quando jat a ganhou; um exército fadado à derrota é aquele que luta primeiro e depois quer vencer".

Finalmente, no que se refere à Sabedoria, algumas das posturas apresentadas certamente causarăo estranheza a qualquer ocidental, sobremaneira àqueles menos versados em filosofia. Contudo, por isso mesmo, essas colocaçôes merecem ser lidas atentamente, para que se descubra o que subjaz a elas: uma clara constatação de que a arte de administrar começa com a administração maior, ou seja, com a administração de nossas vidas, de nossas ambições e anseios, de nossas inseguranças. Somente quando formos capazes de perceber que "o corpo 
se destrói quando é mantido em situação desconfortável"; que "a energia se esvai quando não é resposta"; e que "a mente torna-se opaca quando é usada de modo inapropriado", seremos capazes de perceber que "todas as coisas têm suas conseqüências... porém só os sábios sabem evitar seu desencadeamento; todos os eventos têm suas implicações, mas só os sábios sabem escolhêelas".

Assim, sugerimos a leitura de Estratégia e liderança: as lições dos mestres chineses na visão de um ocidental por todos aqueles que, preocupados com o correto administrar, estejam buscando, mais do que receitas de fácil aplicação e discutível eficiência, o entendimento profundo dessa atividade, suas concepções filosóficas e a raiz dos problemas encontrados nas organizações.

\section{ALLIANCE CAPITALISM: THE SOCIAL ORGANIZATION OF JAPANESE BUSINESS}

de MICHAEL L. GERLACH

Berkeley: University of California Press, 1992.

por Gilmar Masiero, Pesquisador e Professor da Universidade Estadual de Maringá, PR.

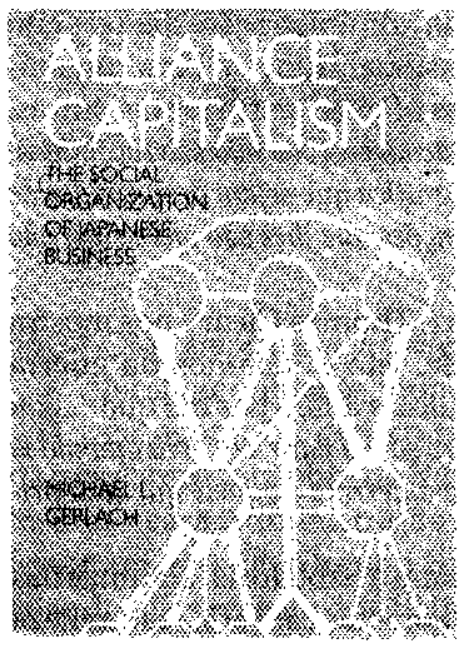

$\mathbf{N}$ os anos 80, o mundo acadêmico discutiu longamente se o excelente desempenho econômico do Japão era devido à sua grande capacidade de poupança e investimento no setor privado ou se era devido a políticas econômicas (industriais) orientadoras desse setor. Nos anos 90, mesmo sem termos uma solu- ção para os debates dos anos 80 , principalmente após as negociações entre os governos americano e japonês sobre os impedimentos estruturais ao livre comércio em 1989, surgem novas explicações para o melhor desempenho da economia japonesa. Este desempenho é devido à sua organização industrial, caracterizada por grandes grupos industriais, comerciais e financeiros.

A década passada também presenciou o surgimento de várias teorias sobre planejamento e administração estratégica. Esta última, nos últimos anos, tem se detido na análise da competitividade das nações e, mais recentemente, dos blocos econômicos, desde a Comunidade Européia, o NAFTA (North American Free Trade Agreement) e aASEAN (Association of South East Asian Nations), até o nosso familiar MERCOSUL. Devido à globalização dos negócios, conceitos como economias de escala, de escopo, fluxos de caixa globais e vantagens competitivas, muitas vezes advindas de orientações governamentais, são hoje senso comuns nas escolas de economia e administração do Oriente e do Ocidente.

Se, no nível das empresas isoladas, as estratégias japonesas são relativamente simples e de fácil compreensão, o mesmo não se pode afirmar sobre a atuação estratégica dos grandes grupos industriais. No nível da empresa, simplificadamente pode-se dizer que os japoneses foram aos Estados Unidos para estudar a maior produtividade das empresas americanas no imediato pósguerra. Voltaram para o Japão e, através de treinamento extensivo e intensivo, adaptaram técnicas americanas aos seus processos produtivos. No processo de adaptação essas técnicas foram "japonisadas" (melhoradas), permitindo hoje melhor desempenho da indústria japonesa.

No nível dos grupos industriais, os keiretsu, a estratégia adotada pelos japoneses, também simplificadamente, teria girado em torno da sua aglutinação forçada pela forte burocracia governamental, traduzida na atuação do MITI - Ministério do Comércio Internacional e da Indústria. Ministério e grandes grupos industriais selecionaram algumas indústrias e mercados-alvo e, através do esforço concentrado e direcionado, conseguiram participação em alguns mercados internacionais. Atualmente esta comunhão de interesses desenvolve produtos sofisticados, direcionados aos segmentos de mercado de renda elevada.

O dramático sucesso econômico japonês despertou a atenção das empresas e economias individuais do Ocidente. Enquanto a participação japonesa na produção mundial de manufaturados cresceu ininterruptamente ao longo dos últimos 40 anos, a produção americana ou de outros países europeus decresceu. Após o encontro no Hotel Plaza, em 1985, no qual o grupo das cinco nações economicamente mais poderosas do mundo (G-5) concordaram que o yen deveria ser valorizado, os japo- 